\title{
Rate of ovarian progesterone secretion and peripheral plasma progesterone levels in unilaterally ovariectomized, pregnant rats
}

\author{
G. T. Meyer and N. W. Bruce \\ Department of Anatomy and Human Biology, The University of Western Australia, Nedlands, \\ Western Australia 6009
}

\begin{abstract}
Summary. Peripheral plasma progesterone concentrations were serially examined in 4 sham-operated and 5 intact rats (controls) and in 5 rats that were unilaterally ovariectomized on Day 8 of gestation. The characteristic rise in progesterone levels after Day 10 appeared to be delayed by 2 days in unilaterally ovariectomized rats but by Day 16 their levels were nearly normal. In a separate experiment a venous outflow technique was used to measure the rate of progesterone secretion from one ovary on Day 16 of gestation of 9 intact rats and the remaining ovary of 5 rats, unilaterally ovariectomized 8 days earlier. The rate of progesterone secretion was almost doubled in the unilaterally ovariectomized rats due to a substantial increase in arterio-venous difference in plasma progesterone levels but no change in ovarian blood flow. This doubling was sufficient to explain the maintenance of peripheral plasma progesterone levels in unilaterally ovariectomized rats without postulating increased secretion from other organs or a decrease in metabolic clearance rate of progesterone.
\end{abstract}

\section{Introduction}

In a previous study (Meyer \& Bruce, 1979b) an attempt was made to stimulate growth and function of corpora lutea by unilaterally ovariectomizing rats on Day 8 of gestation. After 8 days plasma progesterone concentrations were normal but total luteal mass was $50 \%$ less than that in intact control rats. This suggests that the rate of progesterone secretion by the corpora lutea $(C L)$ in the remaining ovary of unilaterally ovariectomized rats is substantially increased with little, if any, increase in tissue mass. Alternatively, plasma progesterone levels may be maintained by increased progesterone secretion from the adrenals (Heap, Holzbauer \& Newport, 1966; Fajer, Holzbauer \& Newport, 1971; Ogle \& Kitay, 1977) or placentas, or by a reduction in the metabolic clearance rate of progesterone.

In the present study an ovarian venous outflow technique (Bruce \& Meyer, 1981) was used to measure progesterone secretion rates directly in unilaterally ovariectomized rats, and serial blood samples were taken to define the precise changes in progesterone levels.

\section{Materials and Methods}

Nulliparous albino Wistar rats, 3-5 months old and weighing $205 \pm 3 \mathrm{~g}$ (mean \pm s.e.m., $\mathrm{N}=$ 28) at mating, were kept in an environmentally controlled building. The day on which spermatozoa were found in a vaginal smear was called Day 1 of gestation. 


\section{Plasma progesterone concentrations}

On Day 8 of pregnancy, each of 14 rats was anaesthetized with ether. A cannula was positioned in the dorsal aorta and a blood sample $(0.3 \mathrm{ml})$ was immediately collected for progesterone assay. Five rats were then unilaterally ovariectomized. Removal of the ovary adjacent to the uterine horn containing the greater number of implantation sites generally resulted in the loss of more than half of the original number of CL. Care was taken to remove the ovary without injury to the uterus or uterine circulation. Four rats were sham-operated: they were anaesthetized and their ovaries and uterine horns were exposed and manipulated in a similar manner. The remaining 5 rats were used as intact controls. The aortic cannula was then passed subcutaneously to emerge from the dorsal neck region so that subsequent samples could be obtained from the conscious animal. Blood samples $(0.3 \mathrm{ml})$ were again collected at $1,2,4$ and $8 \mathrm{~h}$ after the time of ovariectomy (unilaterally ovariectomized rats), or when the ovary was exposed (sham rats), or after the time of the first sample (control rats). After the 4-h sample was taken, $1.0 \mathrm{ml}$ blood from a dioestrous rat was injected into each rat via the aortic cannula. Blood samples were again collected from all rats between 10:00 and 11:00 h on Days 9, 10,12, 14 and 16 of gestation but no donor blood was administered. Rats were conscious during blood collection except when the first sample was taken.

Immediately after blood was collected on Day 16, all rats were killed by an overdose of pentobarbitone sodium. Ovaries were immediately removed and immersed in $10 \%$ formal-saline and later dissected and weighed: fetal and placental weights were also determined. Details of the surgery used and the dissection, weighing and progesterone radioimmunoassay techniques have been described previously (Meyer \& Bruce, 1979a, b). The mean recovery of tritiated progesterone in progesterone-free plasma, collected from adrenalectomized, ovariectomized non-pregnant rats, was $86.2 \pm 3.0 \%$ (s.d., 6 assays). The plasma progesterone concentrations were corrected for procedural losses. The smallest amount of progesterone distinguishable from zero was $10 \mathrm{pg}$. There were no significant cross-reactions with steroids that have been found in rat plasma during pregnancy (see Meyer \& Bruce, 1979b).

When 50,100 and $500 \mathrm{ng} / \mathrm{ml}$ progesterone were added to progesterone-free plasma the progesterone values measured in 6 assays were $52.8 \pm 3 \cdot 7,99.9 \pm 5.2$ and $506.4 \pm 32.2 \mathrm{ng} / \mathrm{ml}$ (mean \pm s.d.) respectively. Duplicate aliquots of the standard concentrations were tested in each assay run to determine inter-assay variation. Intra-assay variation was determined by measuring 10 samples in duplicate in each of 6 assays. The intra-assay and inter-assay coefficients of variation (the standard deviation expressed as a percentage of the mean) were 3.8 and $7.7 \%$ respectively. The results presented in Table 1 and Text-fig. 1 were standardized by multiplying values for each rat, at each time, by the ratio of the mean of all rats at $0 \mathrm{~h}$ to the $0 \mathrm{~h}$ value of that rat.

\section{Measurement of progesterone secretion}

Five rats were unilaterally ovariectomized on Day 8. On Day 16 the mean rate of progesterone secretion from their remaining ovaries was determined and compared with that of 9 control rats, also examined on Day 16. Details of the venous outflow technique and other information on the control rats have been given previously (Bruce \& Meyer, 1981). Important features of the technique were that each rat was anaesthetized with pentobarbitone sodium and, during the measurement period, was partly immersed in a warm saline bath to maintain body temperature and help stabilize arterial pressure. Ovarian blood, collected from the isolated ovarian veins, was measured with a drop counter and immediately returned to the rat, via a jugular cannula, to maintain blood volume. The rate of blood flow was measured during three 20-min intervals and arterial and ovarian venous blood samples were taken for progesterone assay. Progesterone secretion was calculated by multiplying the arterio-venous difference in 
plasma progesterone concentration by the product of ovarian blood flow and the percentage of plasma in whole blood. The average of the three sets of blood flow and progesterone secretion measurements were used as mean values for each rat. At the end of the measurements the rat was killed with an overdose of sodium pentobarbitone. Latex rubber was injected into the parametrial venous cannula to ensure that the ovarian drainage had been correctly isolated. Ovaries were removed for later dissection and weighing. A pregnancy assessment was carried out.

\section{Results}

\section{Serial measurement of plasma progesterone concentrations}

There was no significant difference between the results for the sham-operated and intact control rats; these were pooled and compared against the results of unilaterally ovariectomized rats (Table 1 ; Text-fig. 1$)$.

Table 1. General data from rats unilaterally ovariectomized on Day 8 and examined up to Day 16 of gestation

\begin{tabular}{lcc}
\hline & $\begin{array}{c}\text { Intact } \\
\text { (control and sham) }\end{array}$ & $\begin{array}{c}\text { Unilaterally } \\
\text { ovariectomized }\end{array}$ \\
\hline No. of rats & 9 & 5 \\
No. of implantations & $13 \cdot 6 \pm 0 \cdot 6$ & $13 \cdot 8 \pm 1 \cdot 2$ \\
No. of live fetuses & $13 \cdot 2 \pm 0 \cdot 5$ & $13 \cdot 4 \pm 1 \cdot 2$ \\
No. of CL per rat & $14 \cdot 7 \pm 0 \cdot 5$ & $5 \cdot 4 \pm 0 \cdot 7^{* * *}$ \\
Ovarian tissue weights (mg) $\dagger$ & $47 \cdot 4 \pm 2 \cdot 6$ & $41 \cdot 6 \pm 4 \cdot 0$ \\
$\quad$ Total ovary & $21.4 \pm 1 \cdot 5$ & $18 \cdot 5 \pm 3 \cdot 1$ \\
$\quad$ Stromal tissue & $25 \cdot 9 \pm 1 \cdot 5$ & $23 \cdot 1 \pm 2 \cdot 6$ \\
$\quad$ Luteal tissue & $3 \cdot 75 \pm 0 \cdot 14$ & $4 \cdot 30 \pm 0 \cdot 17^{*}$ \\
$\quad$ Corpus luteum & $215 \pm 6$ & $220 \pm 10$ \\
Fetal weight (mg) & $206 \pm 7$ & $254 \pm 11^{* *}$ \\
Placental weight (mg) &
\end{tabular}

Values given are the group means \pm s.e.m. derived from a single mean value calculated for each rat.

$\dagger$ Ovarian tissue weights refer to the mean of the 2 ovaries in intact rats and the remaining ovary in unilaterally ovariectomized rats.

${ }^{*} P<0.05,{ }^{* *} P<0.01,{ }^{* * *} P<0.001$ compared with value for intact rats (unpaired $t$ test).

Surgery on Day 8 had no apparent effect on fetal survival: the number of implantations on Day 8 was similar to the number of live fetuses on Day 16 (Table 1). The number of CL remaining in unilaterally ovariectomized rats was less than half that in intact rats since the ovary with the greater number of $C L$ was selected for removal at Day 8. Unilateral ovariectomy resulted in a $15 \%$ increase in the mean weight of the remaining CL. Mean placental weight was also significantly increased $(23 \%)$ in unilaterally ovariectomized rats but mean fetal weight was not affected.

Plasma progesterone concentrations in intact rats increased by $85 \%$ during the $60 \mathrm{~min}$ after surgery, returned to around initial values until Day 10, then rose rapidly to peak at Day 14 (Text-fig. 1). In unilaterally ovariectomized rats, progesterone values did not change significantly during the first $60 \mathrm{~min}$ but remained relatively stable until Day 12, then rose rapidly to approach a concentration similar to that of intact rats by Day 16. The rapid rise in the second half of gestation therefore appeared to be delayed by about 2 days in the unilaterally ovariectomized rats. There was no significant difference in haematocrit between intact and unilaterally ovariectomized rats at any sampling time. 

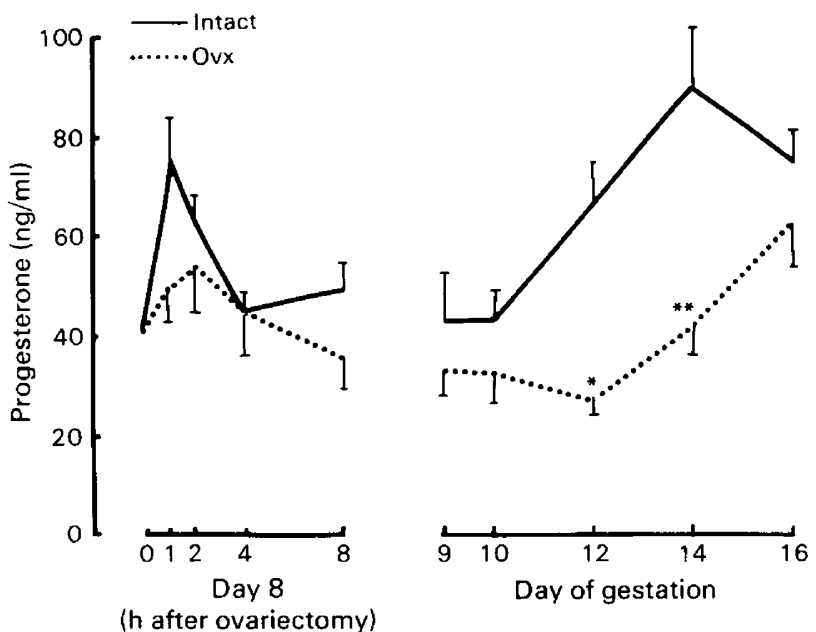

Text-fig. 1. Peripheral plasma progesterone concentrations in 5 unilaterally ovariectomized (Ovx) and 9 intact rats (sham- and un-operated) from Day 8 to Day 16 of gestation. The vertical bars are the standard error of the mean (standardized data: see text). ${ }^{*} P<0.05,{ }^{* *} P<0.01$ compared with value for intact rats (unpaired $t$ test).

\section{Measurement of progesterone secretion}

The mean \pm s.e.m. number of live fetuses in the uterine horn used for blood collection was similar in the control and unilaterally ovariectomized rats $(4.9 \pm 0.6$ and $4.4 \pm 0.7$, respectively) as too were arterial pressure $(130 \pm 4$ and $125 \pm 5 \mathrm{mmHg})$ and haematocrit $(42 \cdot 3 \pm$ 0.6 and $42.3 \pm 1 \cdot 1 \%$ ).

Table 2. Ovarian blood flow and progesterone secretion in rats unilaterally ovariectomized on Day 8 and examined on Day 16 of gestation

\begin{tabular}{|c|c|c|}
\hline & Control & $\begin{array}{c}\text { Unilaterally } \\
\text { ovariectomized }\end{array}$ \\
\hline No. of rats & 9 & 5 \\
\hline \multicolumn{3}{|l|}{ No. of corpora lutea } \\
\hline Both ovaries & $12.8 \pm 0.6$ & $11 \pm 1 \cdot 3$ \\
\hline Ovary used for blood flow measurement & $6 \cdot 1 \pm 0.6$ & $4 \cdot 8 \pm 1 \cdot 0$ \\
\hline \multicolumn{3}{|l|}{ Weight of ovary (mg) } \\
\hline Total ovary & $36 \cdot 7 \pm 3 \cdot 9$ & $48 \cdot 6 \pm 8 \cdot 3$ \\
\hline Luteal tissue & $21 \cdot 3 \pm 2 \cdot 1$ & $22 \cdot 1 \pm 5 \cdot 2$ \\
\hline Stromal tissue & $17 \cdot 4 \pm 2 \cdot 1$ & $26.4 \pm 3 \cdot 3^{*}$ \\
\hline Corpus luteum & $3 \cdot 5 \pm 0 \cdot 1$ & $4 \cdot 5 \pm 0 \cdot 3^{* *}$ \\
\hline \multicolumn{3}{|l|}{ Ovarian blood flow } \\
\hline $\mathrm{ml} / \mathrm{min}$ & $0.48 \pm 0.03$ & $0.44 \pm 0.07$ \\
\hline $\mathrm{ml} / \mathrm{min}$ per $100 \mathrm{~g}$ ovary & $1308 \pm 93$ & $916 \pm 87^{*}$ \\
\hline \multicolumn{3}{|l|}{ Plasma progesterone $(\mathrm{ng} / \mathrm{ml})$} \\
\hline Arterial, 1st sample $\dagger$ & $88 \cdot 7 \pm 4 \cdot 1$ & $68 \cdot 1 \pm 4 \cdot 1^{* *}$ \\
\hline Arterial, at measurement $\ddagger$ & $80 \cdot 5 \pm 3 \cdot 3$ & $61 \cdot 2 \pm 4 \cdot 0^{* *}$ \\
\hline Ovarian venous & $914 \pm 66$ & $1786 \pm 250^{* * *}(\mathrm{~W})$ \\
\hline Arterio-venous difference & $833 \pm 65$ & $1724 \pm 248^{* * *}(\mathrm{~W})$ \\
\hline \multicolumn{3}{|l|}{ Ovarian progesterone secretion rate } \\
\hline$\mu \mathrm{g} / \mathrm{h}$ per ovary & $13 \cdot 7 \pm 1 \cdot 2$ & $25.6 \pm 5.6^{* *}(W)$ \\
\hline$\mu \mathrm{g} / \mathrm{h}$ per mg luteal tissue & $0.66 \pm 0.04$ & $1.19 \pm 0.06^{* * *}$ \\
\hline$\mu \mathrm{g} / \mathrm{h}$ per corpus luteum & $2 \cdot 30 \pm 0.17$ & $5.35 \pm 0.46^{* * *}$ \\
\hline
\end{tabular}

Values given are the group means \pm s.e.m. derived from a single mean value calculated for each rat.

$\dagger 1$ st sample taken immediately carotid cannula was positioned.

$\ddagger 100$ min after Ist sample: see text and Bruce et al. (1980).

${ }^{*} P<0.05 ;^{* *} P<0.01 ;^{* * *} P<0.001$ compared with value for control rats (unpaired $t$ test or (W) Wilcoxon two-sample test when variances were heterogeneous). 
In unilaterally ovariectomized rats the mean number of CL in the ovary used for venous outflow measurement was slightly but not significantly less than that in control rats (Table 2). Corpus luteum weight was $29 \%$ and stromal weight was $52 \%$ greater in the unilaterally ovariectomized rats. The absolute rate of ovarian blood flow was similar in both groups (Table 2). Arterial plasma progesterone levels did not change significantly from the time of the first sample to the time of the venous outflow measurement in either group, but remained about $24 \%$ lower in the unilaterally ovariectomized rats at all times.

The major change found in the unilaterally ovariectomized rats was a substantial increase in the progesterone concentration in the ovarian venous plasma. Since ovarian blood flow was similar in both groups this resulted in an $87 \%$ increase in the rate of progesterone secretion by the ovary (Table 2).

\section{Discussion}

The major finding from the first part of the study was that unilateral ovariectomy on Day 8 of gestation did affect plasma progesterone levels but that these levels approached normal values within 8 days. Any immediate effect of unilateral ovariectomy was unfortunately obscured by early changes in control rat values. Progesterone levels in normal rats are reported to be relatively stable during Days 7-10 of gestation (Morishige, Pepe \& Rothchild, 1973). The present control rat values followed this pattern except that during the first $2 \mathrm{~h}$ after cannulation, progesterone levels rose to almost double initial values. This transitory rise may have been due to the effects of anaesthesia and surgery. The adrenal cortex is able to secrete large amounts of progesterone and, under stress conditions, may even account for as much as half the peripheral progesterone concentration in non-pregnant and pregnant rats (Heap et al., 1966; Fajer et al., 1971; Ogle \& Kitay, 1977). Since an initial transitory rise in plasma progesterone levels was not observed in the unilaterally ovariectomized rats, it is possible that total ovarian progesterone secretion was, at least temporarily, reduced by the operation but that this effect was balanced by an increase in secretion from the adrenals.

Apart from these initial effects, plasma progesterone concentrations were similar in the two groups until about Day 10 but then the rapid rise observed in the control rats was not seen in the unilaterally ovariectomized rats for a further 2 days. Assuming that these patterns reflected changes in ovarian progesterone secretion rates, the progesterone concentrations in unilaterally ovariectomized rats on Days 9 and 10 would have been maintained by a substantial increase in the rate of secretion by the remaining corpora lutea, perhaps augmented by increased secretion from the adrenal cortex. After Day 10, when plasma progesterone levels rose in control rats, there was no further increase in the unilaterally ovariectomized rats since their remaining CL were already secreting at a maximum rate. By Day 12, some form of negative feedback mechanism could have prevailed so that the progesterone secretory capacity of the remaining $\mathrm{CL}$ of the unilaterally ovariectomized rats began to increase relative to that of the controls, resulting in nearly normal plasma progesterone values by Day 16 . The finding that CL were heavier in unilaterally ovariectomized rats suggests that they were subjected to a greater luteotrophic stimulus. The actual stimulus for this, and indeed for the normal increase in progesterone levels after Day 10, is uncertain but it occurs at a time of increasing dominance of placental over pituitary luteotrophins (Morishige \& Rothchild, 1974). The unilaterally ovariectomized rats exhibited placental hypertrophy which has been observed in a number of experimental situations likely to have increased the demand for luteotrophins (Csapo \& Csapo, 1973; Petropoulos, 1973).

The venous outflow study provided direct evidence that the CL of unilaterally ovariectomized rats were stimulated to secrete progesterone at nearly $100 \%$ above their normal rate. This would indicate that, at least at Day 16, neither increased secretion of progesterone by organs other than the ovary, nor a reduction in the metabolic clearance rate of progesterone had 
any significant role in maintaining progesterone levels in the unilaterally ovariectomized rats. Arterial plasma progesterone levels were about $24 \%$ lower in the unilaterally ovariectomized rats, but this may well have reflected the decision to remove the ovary with the greater number of $\mathrm{CL}$. We previously reported that unilaterally ovariectomized rats with 3 or fewer CL remaining had slightly depressed plasma progesterone values at Day 16 (Meyer \& Bruce, 1979b) and there were 2 such rats in the present work.

The $30 \%$ increase in $\mathrm{CL}$ weight in the unilaterally ovariectomized rats was greater than that reported previously (Meyer \& Bruce, 1979b) but this may have been due to 2 of the 5 rats in the present study having only $3 \mathrm{CL}$. In the earlier study it was also found that luteal hypertrophy was greater in rats with 3 or fewer CL. Furthermore, latex rubber was perfused into the ovarian vein, at the end of the venous outflow collection in the present study, and this may have brought out a difference in the volume of the ovarian vasculature in the two groups. This latter possibility might also explain the significant increase in stromal weight in the unilaterally ovariectomized rats: no increase was seen in previous work (Meyer \& Bruce, 1979a, b).

The increased rate of progesterone secretion in unilaterally ovariectomized rats was not accompanied by any change in the absolute rate of ovarian blood flow. Rate of blood flow to the corpus luteum is exceptionally high and changes in progesterone secretion are closely associated with changes in ovarian blood flow in sheep in certain experimental situations (Niswender, Reimers, Diekman \& Nett, 1976). In the rat, however, there appears to be little if any association between ovarian blood flow and progesterone secretion under normal conditions (Bruce, Meyer \& Dimmitt, 1980). Even after haemorrhage, which seems to cause an acute increase in progesterone secretion, ovarian blood flow was unchanged (Bruce \& Meyer, 1981). The present work, involving a more chronic luteotrophic stimulus, extends these findings and indicates that even a prolonged increase in progesterone secretion can be sustained by a normal rate of ovarian blood flow in the rat. At the cellular level unilateral ovariectomy has been shown to induce hypertrophy rather than hyperplasia of luteal cells (Meyer \& Bruce, 1979b) and so the increase in progesterone secretion is related to increased luteal cytoplasm but not cell number.

Although secretion rates of progesterone can be increased over short periods by a variety of acute luteotrophic stimuli (Ichikawa, Morioka \& Sawada, 1972), this is the first direct demonstration of a more sustained increase, achieved at a time of gestation when the normal ovary is already secreting at near maximal rate (Uchida, Kadowaki, Nomura, Miyata \& Miyake, 1970).

We thank Mr S. Parkinson for technical assistance; the Australian Research Grants Council for financial support; and the University of Western Australia for a Research Studentship to G.T.M.

\section{References}

Bruce, N.W. \& Meyer, G.T. (1981) Ovarian blood flow and progesterone secretion in anaesthetized rats at Day 16 of gestation, and the effects of haemorrhage. J. Reprod. Fert. 61, 419-423.

Bruce, N.W., Meyer, G.T. \& Dimmitt, S.B. (1980) Progesterone secretion and ovarian blood flow in the pregnant rat. J. Endocr. 85, 327-330.

Csapo, A.I. \& Csapo, E.F. (1973) Ovariectomy induced placental hypertrophy. Prostaglandins 4, 189-200.

Fajer, A.B., Holzbauer, M. \& Newport, H.M. (1971) The contribution of the adrenal gland to the total amount of progesterone produced in the female rat. $J$. Physiol., Lond. 214, 115-126.
Heap, R.B., Holzbauer, M. \& Newport, H.M. (1966) Adrenal secretion rates of $\mathrm{C}-19$ and $\mathrm{C}-21$ steroids before and after hypophysectomy in the pig and the dog. J. Endocr. 36, 159-176.

Ichikawa, S., Morioka, H. \& Sawada, T. (1972) Acute effect of gonadotrophins on the secretion of progestins by the rat ovary. Endocrinology 90, 13561362.

Meyer, G.T. \& Bruce, N.W. (1979a) The cellular pattern of corpus luteal growth during pregnancy in the rat. Anat. Rec. 193, 823-830.

Meyer, G.T. \& Bruce, N.W. (1979b) Corpus luteum growth and plasma progesterone levels in unilaterally 
ovariectomized pregnant rats. Anat. Rec. 195, 311-316.

Morishige, W.K. \& Rothchild, I. (1974) Temporal aspects of the regulation of corpus luteum function by luteinizing hormone, prolactin and placental luteotrophin during the first half of pregnancy in the rat. Endocrinology 95, 260-273.

Morishige, W.K., Pepe, G.J. \& Rothchild, I. (1973) Serum luteinizing hormone, prolactin and progesterone levels during pregnancy in the rat. Endocrinology 92, 1527-1530.

Niswender, G.D., Reimers, J.J., Diekman, M.A. \& Nett, T.M. (1976) Blood flow: a mediator of ovarian function. Biol. Reprod. 14, 64-81.
Ogle, T.F. \& Kitay, J.1. (1977) Ovarian and adrenal steroids during pregnancy and the oestrous cycle in the rat. J. Endocr, 74, 89-98.

Petropoulos, E.A. (1973) Maternal and fetal factors affecting the growth and function of the rat placenta. Acta endocr., Copenh., Suppl. 176, 9-69.

Uchida, K., Kadowaki, M., Nomura, Y., Miyata, K. \& Miyake, T. (1970) Relationship between ovarian progestin secretion and corpora lutea function in pregnant rats. Endocr. japon. 17, 499-507.

Received 16 February 1982 